\title{
Epidemiologic, clinical, and laboratory findings of the COVID-19 in the current pandemic: systematic review and meta- analysis
}

Yewei Xie ${ }^{1+}$, Zaisheng Wang ${ }^{1+}$, Huipeng Liao ${ }^{1+}$, Gifty Marley ${ }^{1,2}$, Dan Wu ${ }^{1,3}$ and Weiming Tang ${ }^{1,4^{*}}$ (D)

\begin{abstract}
Background: The COVID-19 pandemic has affected the world deeply, with more than 14,000,000 people infected and nearly 600,000 deaths. This review aimed to summarize the epidemiologic traits, clinical spectrum, CT results and laboratory findings of the COVID-19 pandemic.

Methods: We scoped for relevant literatures published during 1st December 2019 to 16th July 2020 based on three databases using English and Chinese languages. We reviewed and analyzed the relevant outcomes.

Results: The COVID-19 pandemic was found to have a higher transmission rate compared to SARS and MERS and involved 4 stages of evolution. The basic reproduction number $\left(R_{0}\right)$ is 3.32 ( $\left.95 \% \mathrm{Cl}: 3.24-3.39\right)$, the incubation period was 5.24 days (95\% Cl:3.97-6.50, 5 studies) on average, and the average time for symptoms onset varied by countries. Common clinical spectrums identified included fever $\left(38.1-39.0^{\circ} \mathrm{C}\right)$, cough and fatigue, with Acute Respiratory Distress Syndrome (ARDS) being the most common complication reported. Body temperatures above $39.0^{\circ} \mathrm{C}$, dyspnea, and anorexia were more common symptoms in severe patients. Aged over 65 years old, having co-morbidities, and developing complications were the commonest high-risk factors associated with severe conditions. Leucopenia and lymphopenia were the most common signs of infection while liver and kidney damage were rare but may cause bad outcomes for patients. The bilateral, multifocal Ground-Glass Opacification (GGO) on peripheral, and the consolidative pulmonary opacity were the most frequent $\mathrm{CT}$ results and the tendency of mortality rates differed by region.

Conclusions: We provided a bird's-eye view of the COVID-19 during the current pandemic, which will help better understanding the key traits of the disease. The findings could be used for disease's future research, control and prevention.
\end{abstract}

Keywords: COVID-19, Epidemiology, Nature history, Clinical spectrum, Laboratory findings

\footnotetext{
* Correspondence: weimingtangscience@gmail.com

${ }^{\dagger}$ Yewei Xie, Zaisheng Wang and Huipeng Liao contributed equally to this work.

1Dermatology Hospital of Southern Medical University, Guangzhou, China

${ }^{4}$ University of North Carolina Project-China, Guangzhou, China

Full list of author information is available at the end of the article
}

\section{BMC}

(c) The Author(s). 2020 Open Access This article is licensed under a Creative Commons Attribution 4.0 International License, which permits use, sharing, adaptation, distribution and reproduction in any medium or format, as long as you give appropriate credit to the original author(s) and the source, provide a link to the Creative Commons licence, and indicate if changes were made. The images or other third party material in this article are included in the article's Creative Commons licence, unless indicated otherwise in a credit line to the material. If material is not included in the article's Creative Commons licence and your intended use is not permitted by statutory regulation or exceeds the permitted use, you will need to obtain permission directly from the copyright holder. To view a copy of this licence, visit http://creativecommons.org/licenses/by/4.0/ The Creative Commons Public Domain Dedication waiver (http://creativecommons.org/publicdomain/zero/1.0/) applies to the data made available in this article, unless otherwise stated in a credit line to the data. 


\section{Background}

The emergence of COVID-19 has made it the first infectious disease pandemic in the twenty-first century. As of 20th July 2020, a total of $14,348,858$ people got infected, and 603,691 were confirmed dead in 213 countries, territories, and areas globally [1]. While more than 30 countries had issued the highest level of response, the SARSCoV-2 (pathogen of COVID-19) continues to spread in different regions around the world [2]. However, the key information on the virus epidemiology, clinical spectrum, and on the pathogen was delayed in response during the early outbreaks in many countries. To fill the research gaps mentioned above, this review article systematically summarizes global findings on the natural history, clinical spectrum, transmission patterns, laboratory findings, CT results, and risk factors of the COVID-19.

\section{Methods}

\section{Search methods for identification of studies}

We searched for publications in epidemiology and clinic domains of the COVID-19 broadly. The databases we searched were: CHKD v3.1 of the CNKI [in Chinese], PubMed, and medRxiv, by using such search terms as 'COVID-19, SARS-CoV-2, and 2019 nCoV' (See Additional file 1). The publication date was restricted from 1st Dec 2019 to 16th Jul 2020. Both English and Chinese were applied for the search. Only the full-text available human studies were eligible for selection. Like the realtime data, other data were obtained from health departments of multiple countries, global NGOs, and reputable media sources.

\section{Data collection and analysis Selection of studies}

The searched records were firstly screened by reading titles and abstracts. Then, the rest records were screened again by full-text reading. If there were disagreements initially, the records then submitted to the whole team for further discussions. Besides, a PRISMA diagram was conducted to illustrate the entire flows of the review (Fig. 1).

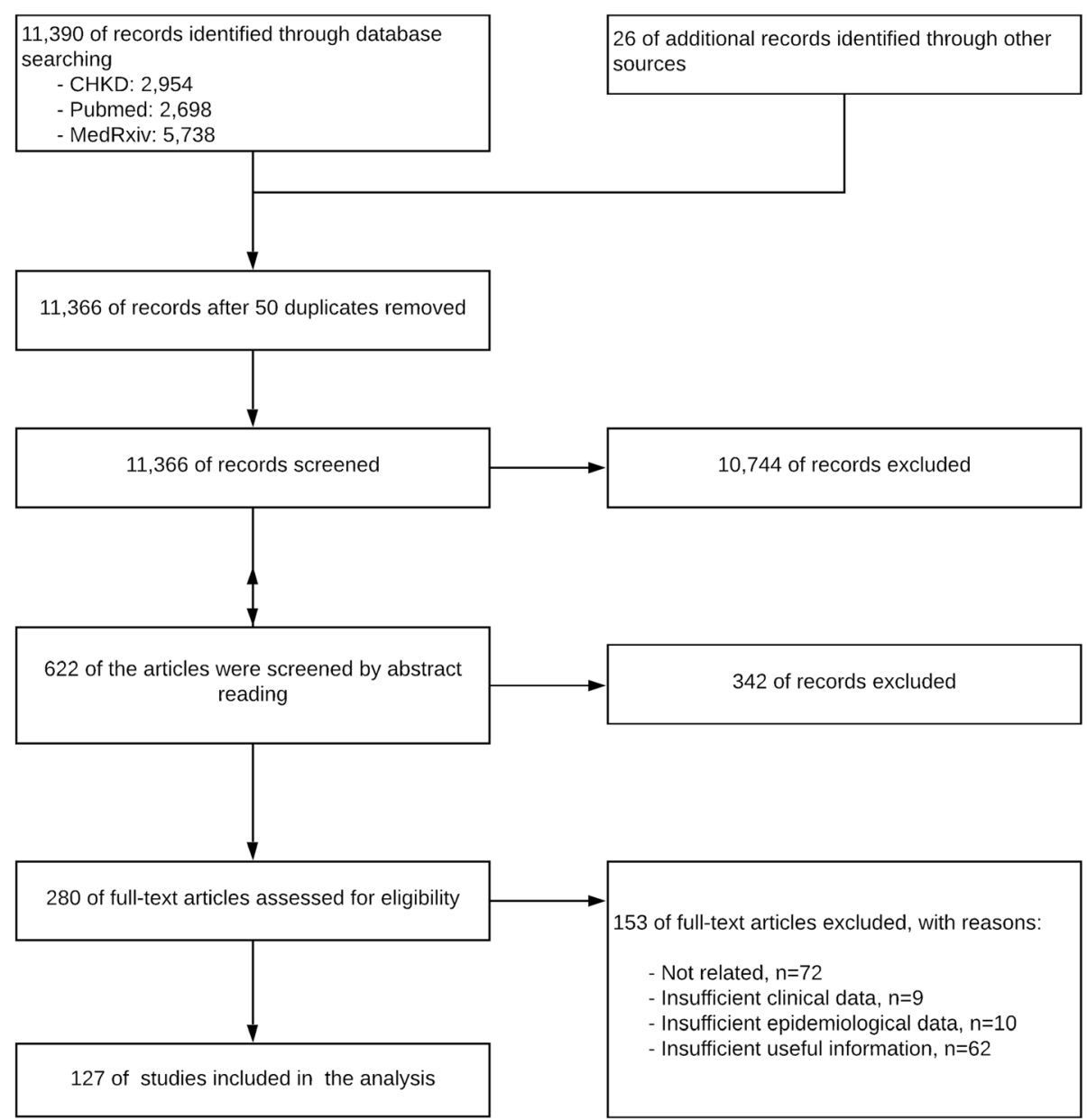

Fig. 1 PRISM flow diagram 


\section{Data extraction, management, and dealing with missing data}

The data for the quantitative analysis was extracted and managed by using Microsoft Excel 2010 (MicrosoftC, Redmond, WA, USA). The meta-analysis was performed by the $R$ version 4.02 and RStudio (2020) [3]. The Cochrane Handbook for Systematic Reviews of Interventions suggested review authors collect missing data from investigators. Considered that using the imputation method to tackle the missing data problem could not reduce bias, we only analyse data available to us if we could not collect the missing data from the investigators [4].

\section{Assessment of heterogeneity and reporting biases, and data synthesis}

The heterogeneity of the included studies was assessed by using $\mathrm{I}^{2}$. The $P$-value was generated by Wald-type test and Likelihood-Ratio test. The overlapping Confidence Intervals (CIs) were displayed by the forest plots (See Additional file 4). We categorized and combined the data about epidemiologic traits, clinical spectrums, laboratory, and imageology findings in a narrative. Then we further analyze the data about common symptoms, reproduction number, and incubation period through meta-analysis. The quantitative outcomes were combined with the narrative of epidemiological and clinical findings.

\section{Results}

We collected 11,366 records after removing duplications. After three batches of screening, 127 records were included in this review (See screening details in Fig. 1).

\section{Epidemiology \\ Demographic characteristics}

In a China based study involving 55,924 COVID-19 patients, the majority of patients were aged 30-69 (77.8\%) with only $2.4 \%$ of the patients being 18 years and below. The median age of the patients was 51 (ranged 2 days100 years old) [5]. Similarly, in the United States, more than half of patients were aged between 20 and 64 years (65\%), with only $5 \%$ of patients being under 19 years old. Older aged patients were more prone to getting infected compared to the young [6]. By gender, the male to female ratio of confirmed cases was 1.06:1.00 in China [7]. However, in South Korea and Iceland, the male population had a higher incidence rate than the female population $[8,9]$. Males had twice the secondary attack rate than females [10].

\section{Transmission stages}

The COVID-19 transmission stages could be categorized into four temporal stages according to the chronological order of case reports. The first stage: people with exposure histories to Huanan Seafood Market (HSM) got infected [11]. Forty-one patients were found to be having SARS-like symptoms in December 2019, and the HSM was believed to be one of the origins of the virus. However, 13 of the 41 patients reported no prior exposure to the HSM thus indicating that the origin of the virus needed further investigation [12]. The second temporal stage is the transition from community transmissions to the outbreak in Wuhan [11]. The virus was mainly spread to multiple communities directly and indirectly by people with HSM exposure histories. The interpersonal transmissions and clustered transmissions formed community transmissions [11]. An earlier study showed that the proportion of patients with HSM exposure histories decreased from 55 to $8.6 \%$ within 22 days, indicating when people who did not have exposure histories to the HSM became infected $[13,14]$. The third stage: the epidemic in China. At this stage, transmissions began to expand to communities outside Wuhan and the Hubei province as a whole [11]. On 26th Jan 2020, a study involving 62 COVID-19 patients outside Wuhan found that all the patients had been exposed to Wuhan, which demonstrated an established local transmission outside Wuhan [15]. The fourth temporal stage is the global pandemic. On 13th Jan 2020, the first case outside China was reported in Thailand [2]. On 30th Jan 2020, the WHO declared a Public Health Emergency of International Concern (PHEIC) [2]. It subsequently took about 51 days for transmission to escalate from the first reported case to the 10,000th reported case outside China. Globally, it took 16 days for the number of reported cases to increase from 10,000th cases to 100,000 th cases, 21 days from 100,000th cases to 500, 000th cases, only 6 days from 500,000 th cases to 1,000 , 000th cases and 13 days from 1,000,000th cases to 2,000, 000th cases [2].

\section{Transmission routes}

The main transmission route of this virus was by human-to-human spread, since only $1.18 \%$ patients among 1099 confirmed patients had history of direct contact with wild animals [16]. The vital transmission routes were through respiratory droplets and contact transmissions. There remains the possibility of aerosol transmission when exposed to high concentrations of aerosols for a long time in a relatively closed environment [17]. Mother-to-child transmission has been confirmed, whiles fecal-oral transmission was also considered possible but lacked direct evidence until now $[18,19]$. Other suspected routes of transmission still needed further clarification.

\section{Transmission patterns}

Community transmission, nosocomial transmission, household transmission, and transmission in closed 
environments were four typical transmission patterns of the COVID-19.

Firstly, community transmission was considered to be an important pattern in COVID-19 spread [5]. In the Netherlands, community transmissions were found in the Noord-Brabant regions [20, 21]. In North America, community transmissions were reported in Winnipeg, Canada, and Eastern Idaho, United States [22, 23].

Secondly, the potential risk of transmission among medical personnel and through medical facilities was deemed high and thus extreme attention should be paid. Transmissions between patients and health workers were in higher proportions during the SARS outbreak, while transmission through medical facilities was higher in proportion during the MERS outbreak [24]. In Wuhan, the proportion of severely infected medical workers was higher than the national average [7]. In Italy, 2629 health workers were reported infected with the COVID-19 before 18th March and accounted for $8.3 \%$ of the total number of cases nationwide. The number however increased to 8358 by 30th March and represented 9\% of the country's total number of cases [25, 26]. In Spain, the number of diagnosed cases among medical workers increased to 5969 within 6 days and more than $12 \%$ of the country's confirmed cases remained among medical workers until March 30th [25]. Update from another source reported an increase in the number of cases from 12 to $14 \%$ among Spain healthcare workers by 31 st March and this was attributed to lack of medical supplies, such as masks and gowns. Other reasons accounting for these high infection rates among medical personnel varied according to different country's circumstances. An Italy study pointed out hospitals as a potential hotspot for infection. Facilities and medical personnel turned into untested vectors and patients [27, 28]. In the US for example, the reasons that turned hospitals into infection hotspots included the overload of COVID-19 patients and inappropriate management against the pandemic in hospitals [29]. Similar to the US, 200 medical workers got infected in a county hospital in Romania due to inadequate hospital management. In Egypt, a serious wave of emigration by physicians for years led to patient overload for remaining medical workers and placed them at higher risk of infection through continuous exposure. The emigration wave was purportedly caused by low salary, undesirable working conditions, lack of legal protection, and shortage of medical supplies and equipment [30].

Thirdly, household transmission contributed to cluster infections and was the major transmission pattern observed in China. For instance, among 1836 reported cases in Guangdong and Sichuan Provinces, most cluster infections occurred in families (78-85\%) [5]. The WHO in this regard issued a statement that household transmission highly occurred among medical workers' families than health facility infection in China. Household transmission was also a significant pattern observed in South Korea and the US [2, 29]. The European Centre for Disease Prevention and Control (ECDC) had provided guidance for the control of household transmission in European countries [5, 31]. What made household transmission worse was that some groups (age $<18$ and $>65$ ) had high risk got infection within households than the general population [32]. So, children and elderly living with medical workers at a higher risk of getting than other populations.

Fourthly, transmissions in a closed environment besides the home should also be of a keen focus on the prevention and control of this outbreak. A Japanese health department reported that a closed environment could promote super-spreading events because the transmission of the SARS-CoV-2 in a closed environment was the same as large-scale transmission, such as the ski chalet-cluster infection in France and the church-hospital infection clusters in South Korea [33]. For example, outbreaks of the COVID-19 were observed in multiple prisons in China, the UK, and the US [7, 34, 35]. Cluster infections also happened on cruise ships, such as the Diamond Princess, Grand Princess, Golden Princess, Ruby Princess, Phoenix Reisen, MS Westerdam, and Punta Arenas [36]. Further studies are however required to identify and assess other potential transmission patterns for further prevention, especially since some cases were asymptomatic [37, 38]. In addition, patients who were considered cured and no longer needed quarantine still tested RT-PCR positive after 5 to 13 days [39].

\section{Nature history}

We systematically used the data of the incubation period and the reproduction numbers for meta-analysis (see details of selected studies on Additional file 2). The result suggested that the mean incubation period was 5.24 days (95\% CI:3.97-6.50, 5 studies), and ranged from 3 to 7.4 days [40-44]. However, the incubation period in some special cases could be as long as 24 days [16]. The result also illustrated that the basic reproduction number $\left(\mathrm{R}_{0}\right)$ of SARS-CoV-2 was 3.32 (95\% CI:3.24-3.39, 14 studies) and varied between 0.6-6.47 [37, 42-53]. This finding suggested that the transmission ability of SARS-CoV-2 was stronger than SARS (3) and MERS $(\leq 1)[54,55]$. Moreover, the median time from the first symptom to first hospital admission was 7 days with the median duration from illness development to severe symptoms development being: 5-8 days for dyspnea, 8-9 days for ARDS, 10.5 days for mechanical ventilation and ICU admission [6, 18]. For COVID-19 related deaths, the duration from the onset of symptoms to death averaged 9 
days in China 5 and in Italy (median) [56], and 10 days in South Korea (median) [9].

\section{Mortality and fatality}

By 14th July 2020, 21 nations had reported over 100,000 COVID-19 cases in each of the countries, together contributed to $81.4 \%$ of the confirmed cases and $81.3 \%$ of death in the world1. The world case fatality rate (CFR) was $4.4 \%$ on 14th July; however, it was apparently different by country. One third of these 21 countries had a CFR of over $4.4 \%$. France (17.4\%), United Kingdom (15.5\%), Italy (14.4\%), and Mexico (11.6\%) were the top four countries with over $10 \%$ CFR while Qatar (0.1\%) and Saudi Arabia (1.0\%) were the two countries with no more than 1\% CFR. Most countries experienced an increase of CFR at first, and the number was then gradually becoming stable during the disease outbreak (Fig. 2). However, the CFR was high in Iran (13.7\% on 27th February) and the United States (7.2\% on 4th March) at first, experienced a sharp decrease to $2.5 \%$ on 8 th March and $1.1 \%$ on 20 th March, and rebounded to 5.0 and $4.0 \%$ on 14th July, respectively. Bangladesh was the only country that had high CFR of around $10 \%$ at the beginning and then continuously decreased until $1.3 \%$ on 14th July. As the pandemic outbreak continued, more surveillance is needed for the CFR of COVID-19 [57].

The mortality is higher among elderly, patients requiring intensive care unit admission and male. However, mortality rate among younger age group and patients with mildly disease is less. The US's data indicated that patients younger than 19 had milder COVID-19 illness, with almost no hospitalizations or deaths reported [6]. Based on a worldwide data, the elderly (aged over 60) were at a high risk of developing into death $[5,6,9,56]$.
The mortality in ICU was extremely higher than NonICU patients, varied from 26 to $78 \%$ [58-61].

About the gender ratio, there is a seemingly unquestionable pattern that COVID-19 killed more men than women [62]. Unlike the less report in the research from China, South Korea or other Asia areas, the reports from Europe and American reflect the male gender is the risk factor for heavy illness. To figure out the general situation around the world, here we analyzed the data from 53 countries, compiled centrally and individually verified by authors against country-specific reports [63], shown that the case-fatality rate among male is about $35 \%$ higher than female (IR $=1.35,95 \%$ Confidence interval: 1.35-1.35) (Table 1). The sex-disparity is consistent across age groups and regions. For example, the incidence rate ratios between male and female were 1.05 (95\% CI: $1.05,1.05), 1.46$ (95\%vCI: $1.46,1.46), 1.46$ (95\% CI: $1.46,1.46), 1.61$ (95\% CI: $1.61,1.61)$ and $1.64(95 \%$ CI: 1.64, 1.64) among COVID-19 cases in Asia, Africa, North America, South America, and Europe, respectively (Table 1). By age groups, COVID-19 cases aged below 60 years old ( $\mathrm{IR}=2.7495 \%$ CI: $2.66-2.82$ ), have wider sex-disparity than those aged above 60 years old (IR = 1.83, 95\% CI: 1.82-1.83), while deaths among cases younger than 40 years old are very rare.

\section{Clinical spectrum \\ Common symptoms}

Based on the data collected from selected articles [12, $15,16,58,64-92$ ] (details of selected articles were put in the Additional file 3), we conducted the meta-analysis using a random-effects model to identify the clinical feature of COVID-19. Fever (76.70, 95\% CI: 64.86-85.44\%) and cough (67.76, 95\% CI: 60.06-74.61\%) were the most

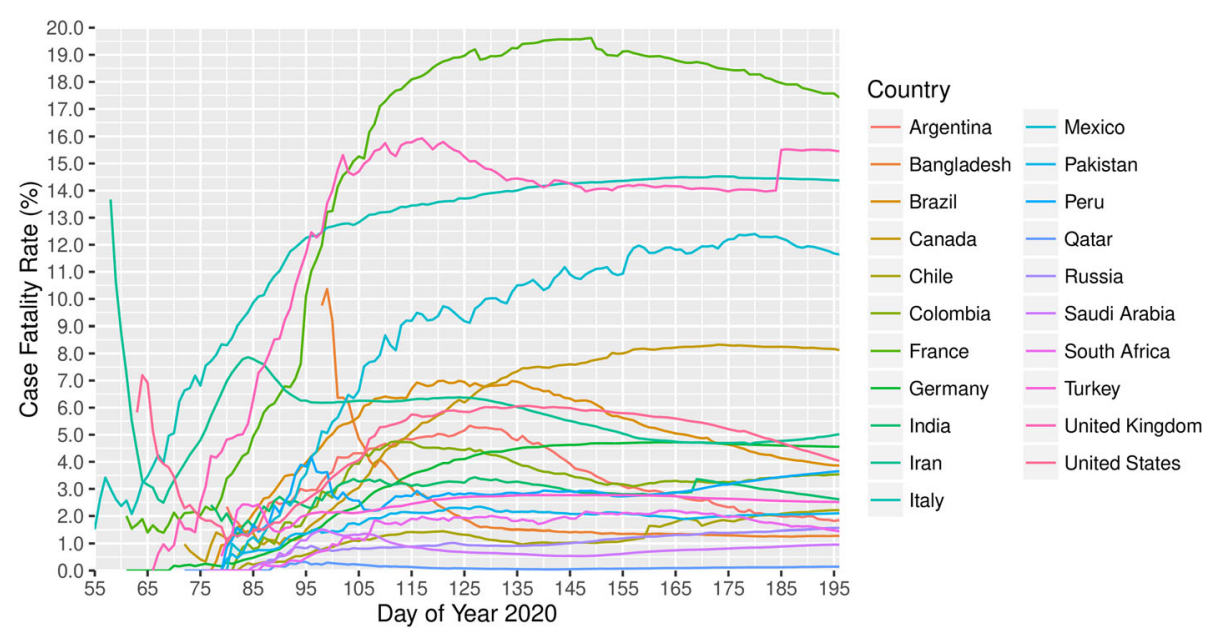

Fig. 2 Case fatality rate of countries reported over 20,000 cases, 2020*. ${ }^{*}$ Data was collected until 14 July 2020 (i.e. the 196th day of year 2020). The CFR of a country was not included on those dates when the country reported less than 100 cases, with the consideration that the CFR may not be reliable if the size of infected population was small 
Table 1 Gender based fatality rate ratio among COVID-19 cases in different region of the world (By July 9th, 2020)

\begin{tabular}{|c|c|c|c|}
\hline \multicolumn{2}{|l|}{ Variables } & \multirow{2}{*}{$\frac{\text { Sex }}{\text { Female }}$} & \multirow{2}{*}{$\frac{\text { Fatality rate ratio }(95 \% \mathrm{Cl})}{1.00}$} \\
\hline Region & Global & & \\
\hline & & Male & $1.35(1.35,1.35)$ \\
\hline & Asia & Female & 1.00 \\
\hline & & Male & $1.05(1.05,1.05)$ \\
\hline & Africa & Female & 1.00 \\
\hline & & Male & $1.46(1.46,1.46)$ \\
\hline & North America & Female & 1.00 \\
\hline & & Male & $1.46(1.46,1.46)$ \\
\hline & South America & Female & 1.00 \\
\hline & & Male & $1.61(1.61,1.61)$ \\
\hline & Europe & Female & 1.00 \\
\hline & & Male & $1.64(1.64,1.64)$ \\
\hline \multirow[t]{10}{*}{ Age } & $<60$ & Female & 1.00 \\
\hline & & Male & $2.74(2.66,2.82)$ \\
\hline & $60-69$ & Female & 1.00 \\
\hline & & Male & $2.36(2.33,2.40)$ \\
\hline & $70-79$ & Female & 1.00 \\
\hline & & Male & $1.76(1.75,1.76)$ \\
\hline & 80 and above & Female & 1.00 \\
\hline & & Male & $1.91(1.91,1.91)$ \\
\hline & 60 and above & Female & 1.00 \\
\hline & & Male & $1.83(1.82,1.83)$ \\
\hline
\end{tabular}

common symptoms. Other common symptoms included: olfactory (44.40\%), gustatory (38.16\%), dyspnea (37.49\%), fatigue (29.93\%), sputum production (17.85\%), sore throat $(16.17 \%)$ and headache $(15.49 \%)$. All the other data showed in Table 2. Besides, studies pointed out that most patients had more than one symptom [68, 70, 71]. Additionally, there were $20.9 \%$ of patients without viral pneumonia symptoms [16], which was opposite to previous studies $[69,70]$. The asymptomatic cases varied from $21.9-49.5 \%[66,68,93,94]$.
The top 3 common symptoms among mild and severe patients are summarized and displayed in a figure (Fig. 3) [12, 16, 61, 70, 95-98]. Fever was found to be the most common symptom in all patients. In a study, $43.8 \%$ of patients had fever initially and the proportion increased to $87.9 \%$ following hospitalization [16]. The body temperatures of $44-47.1 \%$ of patients ranged between $38.1-39.0^{\circ} \mathrm{C}$. The higher body temperatures (above $39.0^{\circ} \mathrm{C}$ ), dyspnea and anorexia were more frequent among patients in severe conditions [16, 64, 98]. Cough and fatigue were more widely reported among mild and severe patients. Additionally, another study reported that dyspnea (76\%) was the most common symptom among severe patients in the United States [99]. The proportion of patients who needed ICU care varied based on the local pandemic circumstances. For example, the WHO speculated that around $13.8 \%$ of patients were in severe conditions in China [5]. However, 23-32\% of patients needed ICU care in Wuhan $[64,69,70]$.

\section{Common complications}

Currently documented COVID-19 related complications include ARDS, arrhythmia, Septic shock, acute cardiac injury, myocarditis, acute coronary syndrome, cardiomyopathy, acute respiratory injury, and acute renal injury, etc. $[58,64,67,69,70,100]$. The ARDS was the most common complication, among both mild and severe patients [58, 64, 67, 69, 70]. Most ICU patients had a higher risk of developing ARDS and having complications [12, 70]. The progress of some patients with ARDS to septic shock was fast and quickly evolved into multiple organ failure finally [69].

\section{Laboratory findings and CT scans Laboratory findings}

Among COVID - 19 patients, a decrease in leukocytes such as eosinophil and lymphocyte were commonly reported. This might be because the cytokine storm caused

Table 2 Meta analyzed results of COVID-19 common clinical symptoms (By July 16th, 2020)

\begin{tabular}{llllll}
\hline & Proportions & $95 \%$ Confidence interval & Heterogeneity test, $\left.\right|^{2}$ & Heterogeneity test, $P$ Value & Number of studies \\
\hline Fever & $76.70 \%$ & $64.86-85.44 \%$ & $99.7 \%$ & 0 & 21 \\
Cough & $67.76 \%$ & $60.06-74.61 \%$ & $99.2 \%$ & $<0.0001$ & 21 \\
Olfactory & $40.80 \%$ & $20.31-65.08 \%$ & $99.4 \%$ & 0 & 14 \\
Gustatory & $34.52 \%$ & $18.83-54.50 \%$ & $98.9 \%$ & $<0.0001$ & 13 \\
Dyspnea & $37.49 \%$ & $26.20-50.34 \%$ & $99.6 \%$ & 0 & 19 \\
Fatigue & $29.93 \%$ & $14.22-52.39 \%$ & $99.7 \%$ & $<0.0001$ & 11 \\
Sputum production & $17.85 \%$ & $9.25-31.65 \%$ & $99.1 \%$ & $<0.0001$ & 10 \\
Sore throat & $16.17 \%$ & $10.05-24.98 \%$ & $96.9 \%$ & $<0.0001$ & 9 \\
Headache & $15.49 \%$ & $7.83-28.33 \%$ & $98.7 \%$ & $<0.0001$ & 12 \\
\hline
\end{tabular}




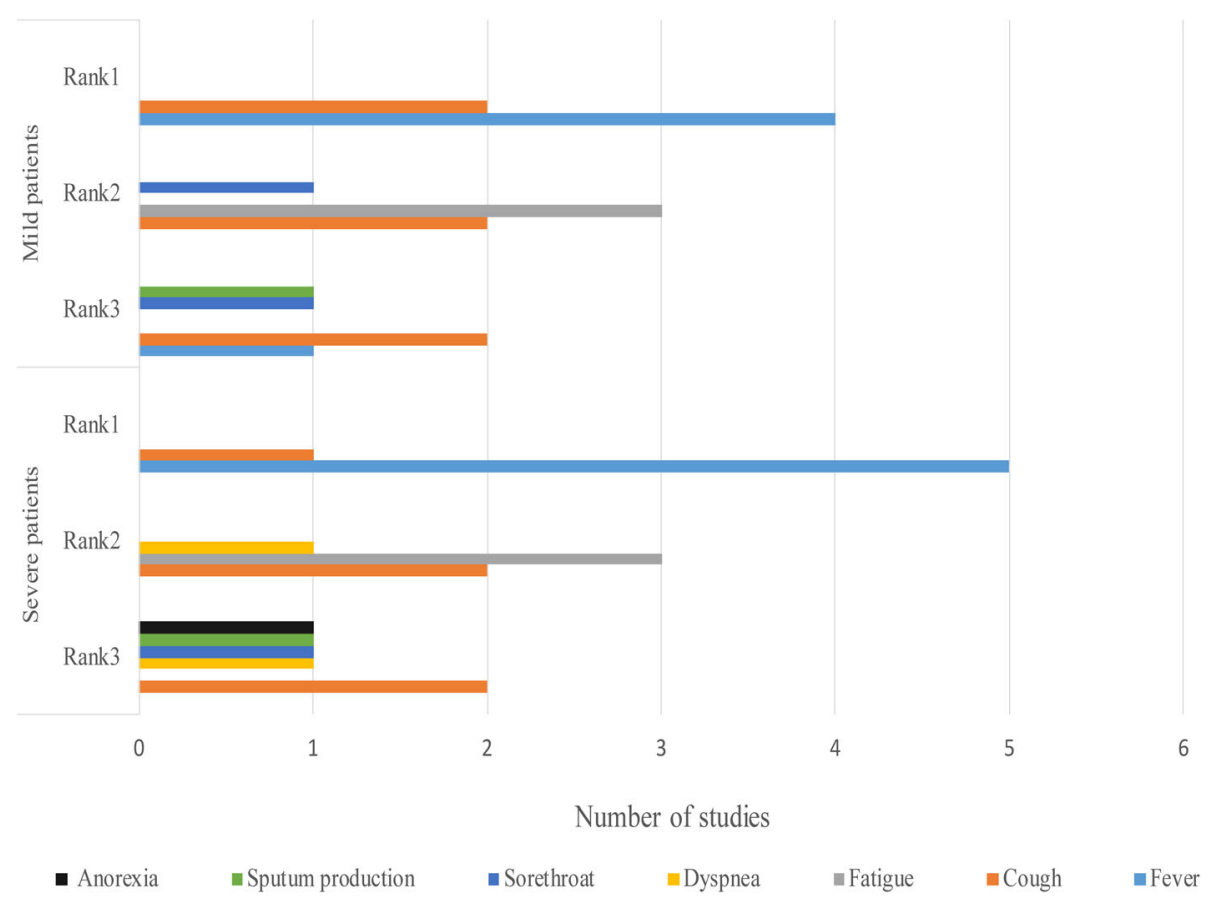

Fig. 3 Comparison of top 3 symptoms among mild and severe patients with COVID-19, 2020*. ${ }^{*}$ The $X$-axis means the number of symptoms reported by how many studies. The Y-axis means symptoms' ranking in mild and severe patients. In this circumstance, rank means the order judged by the frequency of the symptoms reported among studies

by the novel virus changes the peripheral of white blood cells and immune cells $[12,13,15,16,69,70]$. Severe lymphopenia was also common among the dead patients [12, 61]. Myocardial zymogram abnormality was found in many patients. For instance, $76 \%$ of patients had an increase in lactate dehydrogenase, while $13 \%$ of patients had increases in creatine kinase [69]. The level of C-reactive protein was important to evaluate the infection [16]. Most patients were found to have a higher level of C- reactive protein (86\%) and serum ferritin (63\%) compared to the normal range [69]. The biomarkers related to liver and renal damage were found to be abnormal among COVID-19 patients. The abnormality of liver-related biomarkers was not widespread but yet still common in severe cases $[12,15,16,101]$. Besides, although only $7 \%$ of patients showed renal biomarker abnormalities, renal damage might contribute to the final multi-organ failure and death outcome [102, 103].

The ICU patients showed higher levels of white blood cells, neutrophil counts, D-dimer, creatine kinase, and creatine with longer prothrombin times [12, 16, 70]. Compared to patients who survived, the patients who died had higher levels of D-dimer, high-sensitivity cardiac troponin I, serum ferritin, lactate dehydrogenase, IL-6, blood urea, creatinine, white blood cell counts and neutrophil counts. Severe lymphopenia was also common among dead patients [12, 61].

\section{Computed tomography scan (CT scan) features}

The Computed Tomography Scan (CT scan) was widely used for disease diagnosis, prognosis, and management during the COVID-19 [104]. The CT was found more sensitive for identifying SARS-CoV-2 patients than the RT-PCR assay ( $98 \%$ vs. $71 \%$ ) in a study [105]. The CT evidence for confirming the highly suspected patients' positive may precede the RT-PCR results $[106,107]$.

Most patients had GGO and the bilateral lung involvement $[12,69,108-110]$. One study found that bilateral lung involvement was more frequently shown in the intermediate course and late course, compared to the earlier clinical course [107]. The clinical course could be divided into four stages based on CT scan findings [110]. In the first stage (Pre-symptom), GGO, unilateral and multifocal were observed among most patients in this stage $[107,110]$. In the second stage (symptoms $\leq 1$ week), lesions soon developed into bilateral and diffused except for GGO. This stage was considered a period from transition to consolidation. A mixed pattern of transition and consolidation develops during this stage. In the third stage (symptoms 1-2 weeks), the GGO was still common and the consolidation pattern showed. Findings indicated an interstitial change, which was considered as the development of fibrosis. In the fourth stage (symptom 2-3 weeks), consolidation and mixed patterns were more common, and the GGO started to shrink [110], the consolidation was gradually absorbed among patients who recovered at last [111]. 
Among ICU patients, the bilateral multiple lobular and sub segmental areas of consolidation were considered typical findings [12]. Patients in severe condition showed diffuse lesions, with density increasing in both lungs. CT scans showed 'white lung' appearances, indicating the serious influence the infection has on patients' lung functions [112].

\section{Risk factors}

Being old ( $\geq 65$ years old), male sex, having a higher BMI value $\left(>35 \mathrm{Kg} / \mathrm{m}^{2}\right)$, having co-morbidities (e.g. hypertension, diabetes, cardiovascular and cerebrovascular diseases, etc.), and developing complications were vital risk factors for patients to develop severe conditions [59, 70, $78,95,96,113,114]$. The cytokine storm, raised inflammatory markers, elevated cardiac troponins, the requirement of mechanical ventilation, and the requirement of intensive care unit stay predict the bad outcome of admission patients [61].

Findings from multiple studies showed that patients who are more than 65 years of age, with co-morbidities such as diabetes and heart diseases had a high mortality rate $[61,95,115-117]$. Late hospitalization and bacterial infections were also considered high risk factors for disease progression $[69,96,116]$. Smoking history could be a potential risk factor for developing severe conditions $[69,96]$. People with underlying disorders were considered to be at a high risk of getting infected [5].

\section{Discussion}

\section{Research gaps}

Our review identified several research gaps. Firstly, large amounts of data from African were missing from this review. As the number of people in African suffering from malnutrition, anemia, malaria, HIV/AIDs and tuberculosis is high, a large "low immunity population" has been created which has made the control and prevention of COVID-19 in the region a challenge. The situation could be worsened by the limited health resources region [118] and hence, more African focused research is required to support Africa in fighting the epidemic.

Secondly, the proportion of asymptomatic patients is large but the current transmission ability by asymptomatic patients might be weak. However, further exploration of risks posed by the group is needed as limited studies exist on the subject matter [119]. Meanwhile, data on the distribution of asymptomatic patients in large-scale community groups is also lacking, prompting the need for large scale of active screening and testing to help identify them $[93,120]$. This approach is however difficult and expensive for most countries to undertake as accurate strategies to identify asymptomatic currently are non-existent. Further research focus on asymptomatic patients is needed.
Third, a 'super-spreader' was defined as infected individuals who infected numerous others during the SARS outbreak. For example, a nephrotic hospitalized patient who infected 22 people was classified as a 'superspreader' during the SARS in China. 19 in those 22 patients were medical workers who came in contact with the 'super-spreader'. The incidence rate among the medical workers was $59.38 \%(19 / 32)$ in the nephrotic department [121]. In the COVID-19 era, the emergence of 'super-spreaders' were found in multiple places worldwide. A Saudi Arabian study linked the concept of 'super-spreaders' to 'super spreading' events noting that 'super-spreaders' might cause unexpected transmissions during the pilgrimage [122], as huge numbers of people gather. Reasons causing the super-spreading events might include: immune suppression, increased disease severity and viral load, asymptomatic individuals, and extensive social interactions [123]. However, the characteristics and features of how an individual becomes a super-spreader are still not clear [124]. Summarizing the features of the 'super spreader' concept, as well as their characteristics and role in transmissions, are needed in future disease control [125].

Fourth, it has been reported that some cured patients COVID-19 retested positive by PCR after being discharged and quarantined at home in multiple places [39, 126]. The reason for this phenomenon is still unclear and hence further investigations are required for future pandemic control [127].

\section{Limitations}

There existed some limitations in this review. Firstly, this review was based on English and Chinese resources only. As the COVID-19 transformed from a regional outbreak to a global pandemic, comprehensive collection of the related information worldwide is needed. Secondly, the clinical spectrum presented in this review is based on general population only, and thus a further subgroup analyzes in future may help to figure out more on the entire picture of the COVID-19. For instance, although Kawasaki disease was found in children in the UK and Europe countries, other places did not report the gathering Kawasaki disease cases [128].

\section{Conclusions}

The COVID-19 had a stronger transmission ability than SARS and MERS, timely intervention should be conducted to reduce the spread of the disease. The common symptoms included in this study could assist in identifying the potential patients. The summary of the common complications, lab findings, CT features and risk factors could help medical personnel better manage patients who may develop into severe conditions or death. 


\section{Supplementary information}

Supplementary information accompanies this paper at https://doi.org/10. 1186/s12879-020-05371-2.

\section{Additional file 1. Searching Terms.}

Additional file 2. Detail of selected studies for meta-analysis (RO\&Incubation period).

Additional file 3. Detail of selected studies for clinical symptoms' metaanalysis.

Additional file 4. The forest plots of clinical symptoms' meta-analysis.

\section{Abbreviations}

ARDS: Acute Respiratory Distress Syndrome; CFR: Case Fatality Rate; COVID19: Coronavirus disease 2019; CT: Computed Tomography Scan; ECDC: The European Centre for Disease Prevention and Control; GGO: Ground-Glass Opacification; ICU: Intensive care unit; MERS: Middle East respiratory syndrome-related corona virus; PCR: Polymerase chain reaction; $R_{0}$ : Basic reproduction number; SARS: Severe acute respiratory syndrome; SARS-CoV2: Severe acute respiratory syndrome corona virus 2; WHO: World Health Organization

\section{Acknowledgements}

We thank Mr. Peizhen Zhao for technical support.

\section{Authors' contributions}

WT designed the study protocol. $Y X, Z W$, and $H L$ did the literature search. The titles, abstracts, and full texts were screened and selected by $Y X, Z W$, and $\mathrm{HL}$. The data were extracted and analysed by $Y W, Z W$ and HL. YX, ZW and $\mathrm{HL}$ drafted the manuscript. YX, ZW, GM, DW, and WT edited the draft. All authors read and approved the final manuscript.

\section{Funding}

This work was supported by the National Key Research and Development Program of China (2017YFE0103800), NIMH (R34MH119963), National Science and Technology Major Project (2018ZX10101-001-001-003), and the National Nature Science Foundation of China (81903371). The funders had no role in study design, data collection, and analysis, decision to publish, or preparation of the manuscript.

\section{Availability of data and materials}

The key information and data generated and/or analyzed during this study were included in this article and/or its supplementary information files.

\section{Ethics approval and consent to participate}

Not applicable.

\section{Consent for publication}

Not applicable.

\section{Competing interests}

Dr.Weiming Tang is the Associate Editor of this journal.

\section{Author details}

'Dermatology Hospital of Southern Medical University, Guangzhou, China

${ }^{2}$ School of Public Health, Nanjing Medical University, Nanjing, China.

${ }^{3}$ London School of Hygiene \& Tropical Medicine, London, UK. ${ }^{4}$ University of North Carolina Project-China, Guangzhou, China.

Received: 7 May 2020 Accepted: 25 August 2020

Published online: 31 August 2020

\section{References}

1. WHO. Situation report - 182. https://www.who.int/docs/default-source/ coronaviruse/situation-reports/20200720-covid-19-sitrep-182.pdf?sfvrsn= 60 aabc5c 2. Accessed 21 July 2020

2. WHO. Rolling updates on coronavirus disease (COVID-19) https://www.who. int/emergencies/diseases/novel-coronavirus-2019/events-as-they-happen. Accessed 15 July 2020
3. RStudio. RStudio: integrated development for R. Boston, MA: RStudio, PBC; 2020

4. Higgins JPT TJ, Chandler J, Cumpston M, Li T, Page MJ, Welch VA. Cochrane, 2019. www.training.cochrane.org/handbook. Accessed 25 May 2020.

5. WHO. Report of the WHO-China Joint Mission on Coronavirus Disease 2019 (COVID-19). https://www.who.int/docs/default-source/coronaviruse/whochina-joint-mission-on-covid-19-final-report.pdf. Accessed 25 May 2020.

6. CDC COVID-19 Response Team. Severe Outcomes Among Patients with Coronavirus Disease 2019 (COVID-19) —United States, February 12-March 16, 2020. https://www.cdc.gov/mmwr/volumes/69/wr/pdfs/mm6912e2-H. pdf. Accessed 25 May 2020.

7. Epidemiology Working Group for NCIP Epidemic Response. The epidemiological characteristics of an outbreak of 2019 novel coronavirus diseases (COVID-19) in China. Chin J Epidemiol. 2020;41(2):145-51.

8. Gudbjartsson DF, Helgason A, Jonsson H, Magnusson OT, Melsted P, Norddahl GL, et al. Spread of SARS-CoV-2 in the Icelandic population. N Engl J Med. 2020;382(24):2302-15.

9. Jeong EK, Park O, Park YJ, Park SY, Kim YM, Kim J, et al. Coronavirus disease19: The first 7,755 cases in the Republic of Korea. Osong Public Health Res Perspect. 2020;11(2):85-90.

10. COVID-19 National Emergency Response Center, Epidemiology and Case Management Team, Korea Centers for Disease Control and Prevention. Coronavirus Disease-19: Summary of 2,370 Contact Investigations of the First 30 Cases in the Republic of Korea. Osong Public Health Res Perspect. 2020;11(2):81-4 10.

11. Special Expert Group for Control of the Epidemic of Novel Coronavirus Pneumonia of the Chinese Preventive Medicine Association. An update on the epidemiological characteristics of novel coronavirus pneumonia (COVID19). Chin J Epidemiol. 2020;41(2):139-44.

12. Huang $C$, Wang $Y, L i X$, Ren $L$, Zhao J, Hu Y, et al. Clinical features of patients infected with 2019 novel coronavirus in Wuhan, China. Lancet. 2020;395(10223):497-506.

13. J-j Z, Dong X, Cao Y-Y, Yuan Y-D, Yang Y-B, Yan Y-Q, et al. Clinical characteristics of 140 patients infected with SARS-CoV-2 in Wuhan, China. Allergy vol. 2020;75(7):1730-1741.

14. Li Q, Guan X, Wu P, Wang X, Zhou L, Tong Y, et al. Early transmission dynamics in Wuhan, China, of novel coronavirus-infected pneumonia. N Engl J Med. 2020;382(13):1199-207.

15. $X u X-W, W u X-X$, Jiang $X-G, X u K-J$, Ying $L-J, M a ~ C-L$, et al. Clinical findings in a group of patients infected with the 2019 novel coronavirus (SARS-Cov-2) outside of Wuhan, China: retrospective case series. BMJ. 2020;368:m606.

16. W-j G, Ni Z-Y, Hu Y, Liang W-H, Ou C-Q, He J-X, et al. Clinical characteristics of coronavirus disease 2019 in China. N Engl J Med. 2020;382(18):1708-20.

17. National Health Commission of the PRC. Novel coronavirus pneumonia prevention and control program (Sixth Edition). http://www.nhc.gov.cn/jkj/ s3577/202003/4856d5b0458141fa9f376853224d41d7/files/4132bf035bc2424 78a6eaf157eb0d979.pdf. Accessed 25 May 2020.

18. Yeo C, Kaushal S, Yeo D. Enteric involvement of coronaviruses: is faecal-oral transmission of SARS-CoV-2 possible? Lancet Gastroenterol Hepatol. 2020; 5(4):335-7.

19. Vivanti AJ, Vauloup-Fellous C, Prevot S, Zupan V, Suffee C, Do Cao J, et al. Transplacental transmission of SARS-CoV-2 infection. Nat Commun. 2020; 11(1):3572.

20. (RIVM) RvVeM. COVID-19: Nieuwe aanwijzing voor inwoners Noord-Brabant. [COVID-19: Advice for residents of Noord-Brabant]. Bilthoven: RIVM; 2020.

21. Reusken CB, Buiting A, Bleeker-Rovers C, Diederen B, Hooiveld M, Friesema I, et al. Rapid assessment of regional SARS-CoV-2 community transmission through a convenience sample of healthcare workers, the Netherlands, march 2020. Euro Surveill. 2020;25(12):2000334.

22. CBC News. Community transmission of COVID-19 detected in Winnipeg, public health officials say. https://www.cbc.ca/news/canada/manitoba/ manitoba-covid-19-briefing-1.5517379. Accessed 25 May 2020.

23. Localnews8. Community transmission of COVID-19 identified in Teton County, more cases in Custer and Bonneville. https://localnews8.com/ health/coronavirus/2020/04/01/community-transmission-of-covid-19identified-in-teton-county-more-cases-in-custer-and-bonneville-counties/. Accessed 25 May 2020.

24. Chowell G, Abdirizak F, Lee S, Lee J, Jung E, Nishiura H, et al. Transmission characteristics of MERS and SARS in the healthcare setting: a comparative study. BMC Med. 2020;13(1):1-12. 
25. NBC News. Medical workers in Spain and Italy 'overloaded' as more of them catch coronavirus. https://www.nbcnews.com/news/world/medical-workersspain-italy-overloaded-more-them-catch-coronavirus-n1170721. Accessed 25 May 2020.

26. AJazeera News. Thousands of medical staff infected with coronavirus in Italy. https://www.aljazeera.com/news/2020/03/rising-number-medical-staffinfected-coronavirus-italy-200318183939314.html. Accessed 25 May 2020.

27. Nacoti M, Ciocca A, Giupponi A, Brambillasca P, Lussana F, Pisano M, et al. At the epicenter of the Covid-19 pandemic and humanitarian crises in Italy: changing perspectives on preparation and mitigation. NEJM Catalyst Innovations in Care Delivery. 2020;1(2).

28. Spina S, Marrazzo F, Migliari M, Stucchi R, Sforza A, Fumagalli R. The response of Milan's Emergency Medical System to the COVID-19 outbreak in Italy. Lancet. 2020;395(10227):e49-50.

29. NY Times. Nurses Die, Doctors Fall Sick and Panic Rises on Virus Front Lines https://www.nytimes.com/2020/03/30/nyregion/ny-coronavirus-doctors-sick. html. Accessed 25 May 2020.

30. Weekly TA. Poor working conditions hamper Egypt's medical professionals effort to stop spread of virus. https://thearabweekly.com/poor-workingconditions-hamper-egypts-medical-professionals-effort-stop-spread-virus. Accessed 25 May 2020.

31. European Centre for Disease Prevention and Control. Infection prevention and control in the household management of people with suspected or confirmed coronavirus disease (COVID-19). https://www.ecdc.europa.eu/ sites/default/files/documents/Home-care-of-COVID-19-patients-2020-03-31. pdf. Accessed 25 May 2020.

32. Xu X-K, Liu X-F, Wang L, Ali ST, Du Z, Bosetti P, et al. Household transmissions of SARS-CoV-2 in the time of unprecedented travel lockdown in China. Preprint at https://www.medrxiv.org/content/10.1101/2020.03.02.2 0029868v2. Accessed 31 Mar 2020.

33. Nishiura H, Oshitani $H$, Kobayashi $T$, Saito $T$, Sunagawa T, Matsui $T$, et al. Closed environments facilitate secondary transmission of coronavirus disease 2019 (COVID-19). Preprint at https://www.medrxiv.org/content/10.11 01/2020.02.28.20029272v1C. Accessed 20 Mar 2020.

34. LSE. COVID-19: Time to reduce the prison population in England and Wales. https://blogs.Ise.ac.uk/politicsandpolicy/covid-19-prison-population/. Accessed 25 May 2020.

35. News. C. Prisoners, Police and the Pandemic: Heinz College criminologist and public policy expert Daniel Nagin discusses disease transmission within the prison system. https://www.cmu.edu/news/stories/archives/2020/march/ prisoners-pandemics.html. Accessed 25 May 2020.

36. ABC News. COVID-19, Cruise ship "nightmare". https://www.abc.net.au/ chinese/2020-04-04/the-cruises-hit-by-coronavirus/12120864. Accessed 25 May 2020.

37. Pan X, Chen D, Xia Y, Wu X, Li T, Ou X, et al. Asymptomatic cases in a family cluster with SARS-CoV-2 infection. Lancet Infect Dis. 2020;20(4):410-1.

38. Bai $Y$, Yao L, Wei T, Tian F, Jin D-Y, Chen L, et al. Presumed asymptomatic carrier transmission of COVID-19. JAMA. 2020;323(14):1406-7.

39. Lan $L, X u$ D, Ye G, Xia C, Wang S, Li Y, et al. Positive RT-PCR test results in patients recovered from COVID-19. JAMA. 2020;323(15):1502-3.

40. Kucharski AJ, Russell TW, Diamond C, Liu Y, Edmunds J, Funk S, Eggo RM. Early dynamics of transmission and control of COVID-19: a mathematical modelling study. Lancet Infect Dis. 2020;20(5):553-8.

41. Linton NM, Kobayashi T, Yang Y, Hayashi K, Akhmetzhanov AR, Jung S-M, et al. Incubation period and other epidemiological characteristics of 2019 novel coronavirus infections with right truncation: a statistical analysis of publicly available case data. J Clin Med. 2020;9(2):538.

42. Backer JA, Klinkenberg D, Wallinga JJE. Incubation period of 2019 novel coronavirus (2019-nCoV) infections among travellers from Wuhan, China, 20-28 January 2020. Euro surveill. 2020;25(5):2000062.

43. Song Q, Zhao H, Fang L, Liu W, Zheng C, Zhang Y. Study on assessing early epidemiological parameters of coronavirus disease epidemic in China. Chin J Epidemiol. 2020;41(4):461-5.

44. Wang P, Lu J, Jin Y, Zhu M, Wang L, Chen SJ. Epidemiological characteristics of 1212 COVID-19 patients in Henan, China. Preprint at https://www. medrxiv.org/content/10.1101/2020.02.21.20026112v2.full.pdf. Accessed 20 Mar 2020

45. Li J, Wang Y, Gilmour S, Wang M, Yoneoka D, Wang Y, et al. Estimation of the epidemic properties of the 2019 Novel coronavirus: a mathematical modeling study. Preprint at https://ssrn.com/abstract=3542150. Accessed 20 Mar 2020.
46. Wu JT, Leung K, Leung GM. Nowcasting and forecasting the potential domestic and international spread of the 2019-nCoV outbreak originating in Wuhan, China: a modelling study. Lancet. 2020;395(10225):689-97.

47. Shen M, Peng Z, Xiao Y, Zhang L. Modeling the epidemic trend of the 2019 novel coronavirus outbreak in China. Preprint at https://www.biorxiv.org/ content/10.1101/2020.01.23.916726v1.full.pdf. Accessed 20 Mar 2020.

48. Zhao S, Lin Q, Ran J, Musa SS, Yang G, Wang W, et al. Preliminary estimation of the basic reproduction number of novel coronavirus (2019-nCoV) in China, from 2019 to 2020: a data-driven analysis in the early phase of the outbreak. Int J Infect Dis. 2020;92:214-7.

49. Read JM, Bridgen JR, Cummings DA, Ho A, Jewell CPJM. Novel coronavirus 2019-nCoV: early estimation of epidemiological parameters and epidemic predictions. Preprint at https://www.medrxiv.org/content/10.1101/2020. 01.23.20018549v2.full.pdf. Accessed 20 Mar 2020.

50. Zhang S, Diao M, Yu W, Pei L, Lin Z, Chen D. Estimation of the reproductive number of novel coronavirus (COVID-19) and the probable outbreak size on the Diamond Princess cruise ship: A data-driven analysis. Int J Infect Dis. 2020;93:201-4.

51. Liu T, Hu J, Xiao J, He G, Kang M, Rong Z, et al. Time-varying transmission dynamics of novel coronavirus pneumonia in China. Preprint at https:// www.biorxiv.org/content/10.1101/2020.01.25.919787v2.full.pdf. Accessed 20 Mar 2020.

52. Tang B, Wang X, Li Q, Bragazzi NL, Tang S, Xiao Y, et al. Estimation of the transmission risk of the 2019-nCoV and its implication for public health interventions. J Clin Med. 2020;9(2):462.

53. Liu T, Hu J, Kang M, Lin L, Zhong H, Xiao J, et al. Transmission dynamics of 2019 novel coronavirus (2019-nCoV). Preprint at https://ssrn.com/abstract= 3526307. Accessed 20 Mar 2020.

54. Bauch CT, Lloyd-Smith JO, Coffee MP, Galvani APJE. Dynamically modeling SARS and other newly emerging respiratory illnesses: past, present, and future. Epidemiology. 2005;16(6):791-801.

55. Bauch CT, Oraby TJTL. Assessing the pandemic potential of MERS-CoV. Lancet. 2013;382(9893):662-4.

56. COVID-19 Surveillance Group. Characteristics of COVID-19 patients dying in Italy: Report based on available data on March 26th, 2020. https://www. epicentro.iss.it/coronavirus/bollettino/Report-COVID-2019_26_marzo_eng. pdf. Accessed 25 May 2020.

57. European Centre for Disease Prevention and Control. Download today's data on geographic distribution of COVID-19 cases worldwide. https://www. ecdc.europa.eu/en/publications-data/download-todays-data-geographicdistribution-covid-19-cases-worldwide. Accessed on 22 April 2020.

58. Argenziano MG, Bruce SL, Slater CL, Tiao JR, Baldwin MR, Barr RG, et al. Characterization and clinical course of 1000 patients with coronavirus disease 2019 in New York: retrospective case series. BMJ. 2020;369:m1996.

59. Petrilli CM, Jones SA, Yang J, Rajagopalan H, O'Donnell L, Chernyak Y, et al. Factors associated with hospital admission and critical illness among 5279 people with coronavirus disease 2019 in New York City: prospective cohort study. BMJ. 2020;369:m1966.

60. Grasselli G, Zangrillo A, Zanella A, Antonelli M, Cabrini L, Castelli A, et al. Baseline characteristics and outcomes of 1591 patients infected with SARSCoV-2 admitted to ICUs of the Lombardy region, Italy. JAMA. 2020;323(16): 1574-81.

61. Zhou F, Yu T, Du R, Fan G, Liu Y, Liu Z, et al. Clinical course and risk factors for mortality of adult in patients with COVID-19 in Wuhan, China: a retrospective cohort study. Lancet. 2020;395(10229):1054-62.

62. Pareek M, Bangash MN, Pareek N, Pan D, Sze S, Minhas JS, et al. Ethnicity and COVID-19: an urgent public health research priority. Lancet. 2020; 395(10234):1421-2.

63. $5050 \mathrm{GH}$. COVID-19 sex-disaggregated data tracker-Sex, gender and COVID19. https://globalhealth5050.org/covid19/\#1586352650173-d9a8b64b-670a. Accessed 25 May 2020.

64. Hong KS, Lee KH, Chung JH, Shin K-C, Choi EY, Jin HJ, et al. Clinical features and outcomes of 98 patients hospitalized with SARS-CoV-2 infection in Daegu, South Korea: a brief descriptive study. Yonsei Med J. 2020;61(5):4317.

65. Qasim M, Yasir M, Ahmad W, Yoshida M, Azhar M, Ali MA, et al. Early epidemiological and clinical manifestations of COVID-19 in Japan. Preprint at https://www.medrxiv.org/content/10.1101/2020.04.17.20070276v1.full.pdf. Accessed 5 July 2020.

66. Shabrawishi M, Al-Gethamy MM, Naser AY, Ghazawi MA, Alsharif GF, Obaid EF, et al. Clinical, radiological and therapeutic characteristics of patients with 
COVID-19 in Saudi Arabia. Preprint at https://www.medrxiv.org/content/ 0.1101/2020.05.07.20094169v2.full.pdf. Accessed 5 July 2020.

67. Pongpirul WA, Wiboonchutikul S, Charoenpong L, Panitantum N, Vachiraphan A, Uttayamakul S, et al. Clinical course and potential predicting factors of pneumonia of adult patients with coronavirus disease 2019 (COVID-19): a retrospective observational analysis of 193 confirmed cases in Thailand. Preprint at https:/www.medrxiv.org/content/10.1101/2020.06.24.2 0139642v1.full.pdf. Accessed 5 July 2020.

68. Almazeedi S, Al-Youha S, Jamal MH, Al-Haddad M, Al-Muhaini A, Al-Ghimlas $F$, et al. Characteristics, risk factors and outcomes among the first consecutive 1096 patients diagnosed with COVID-19 in Kuwait. Preprint at https://www.medrxiv.org/content/10.1101/2020.05.09.20096495v1.full.pdf. Accessed 5 July 2020.

69. Chen N, Zhou M, Dong X, Qu J, Gong F, Han Y, et al. Epidemiological and clinical characteristics of 99 cases of 2019 novel coronavirus pneumonia in Wuhan, China: a descriptive study. Lancet. 2020;395(10223):507-13.

70. Wang D, Hu B, Hu C, Zhu F, Liu X, Zhang J, et al. Clinical characteristics of 138 hospitalized patients with 2019 novel coronavirus-infected pneumonia in Wuhan, China. JAMA. 2020;323(11):1061-9.

71. Docherty AB, Harrison EM, Green CA, Hardwick HE, Pius R, Norman L, et al. Features of 20133 UK patients in hospital with covid-19 using the ISARIC WHO clinical characterization protocol: prospective observational cohort study. BMJ. 2020;369:m1985.

72. Rojo JMC, Santos JMA, Núñez-Cortés JM, Bermejo CL, Rincón JMR, RoyVallejo E, et al. Clinical characteristics of patients hospitalized with COVID-19 in Spain: results from the SEMI-COVID-19 network. Preprint at https://www. medrxiv.org/content/10.1101/2020.05.24.20111971v1.full.pdf. Accessed 5 July 2020.

73. Regina J, Papadimitriou-Olivgeris M, Burger R, Filippidis P, Tschopp J, Desgranges $F$, et al. Epidemiology, risk factors and clinical course of SARSCoV-2 infected patients in a Swiss university hospital: an observational retrospective study. Preprint at https://www.medrxiv.org/content/10.1101/2 020.05.11.20097741v1.full.pdf. Accessed 5 July 2020.

74. Boddington NL, Charlett A, Elgohari S, Walker JL, Mcdonald H, Byers C, et al. COVID-19 in Great Britain: epidemiological and clinical characteristics of the first few hundred (FF100) cases: a descriptive case series and case control analysis. Preprint at https://www.medrxiv.org/content/10.1101/2020. 05.18.20086157v1.full.pdf. Accessed 5 July 2020.

75. Colaneri M, Sacchi P, Zuccaro V, Biscarini S, Sachs M, Roda S, et al. Clinical characteristics of coronavirus disease (COVID-19) early findings from a teaching hospital in Pavia, North Italy, 21 to 28 February 2020. Euro Surveill. 2020;25(16):2000460

76. Ortiz-Brizuela E, Villanueva-Reza M, González-Lara MF, Tamez-Torres KM, Román-Montes CM, Díaz-Mejía BA, et al. Clinical and epidemiological characteristics of patients diagnosed with COVID-19 in a tertiary care center in Mexico CITY: a prospective cohort study. Rev Investig Clin. 2020;72(3): 165-77.

77. Shekhar R, Sheikh AB, Upadhyay S, Atencio J, Kapuria DJID. Early experience with COVID-19 patients at academic hospital in southwestern United States. Infect Dis (Lond). 2020;52(8):596-9.

78. Suleyman G, Fadel RA, Malette KM, Hammond C, Abdulla H, Entz A, et al. Clinical characteristics and morbidity associated with coronavirus disease 2019 in a series of patients in metropolitan Detroit. JAMA Netw Open. 2020; 3(6):e2012270

79. Goyal P, Choi JJ, Pinheiro LC, Schenck EJ, Chen R, Jabri A, et al. Clinical characteristics of Covid-19 in New York city. N Engl J Med. 2020;382(24): 2372-4.

80. de Souza WM, Buss LF, da Silva Candido D, Carrera JP, Li S, Zarebski A, et al. Epidemiological and clinical characteristics of the early phase of the COVID19 epidemic in Brazil. Preprint at https://www.medrxiv.org/content/10.11 01/2020.04.25.20077396v1.full.pdf. Accessed 5 July 2020.

81. Beltrán-Corbellini Á, Chico-García JL, Martínez-Poles J, Rodríguez-Jorge F, Natera-Villalba E, Gómez-Corral J, et al. Acute-onset smell and taste disorders in the context of COVID-19: a pilot multicentre polymerase chain reaction based case-control study. Preprint at https://www.medrxiv.org/ content/10.1101/2020.04.25.20077396v1.full.pdf. Accessed 5 July 2020.

82. Bénézit $F$, Le Turnier $P$, Declerck $C$, Paillé $C$, Revest $M$, Dubée $V$, et al. Utility of hyposmia and hypogeusia for the diagnosis of COVID-19. Lancet Infect Dis. 2020;51473-3099(20):30297-8.

83. Giacomelli A, Pezzati L, Conti F, Bernacchia D, Siano M, Oreni L, et al. Selfreported olfactory and taste disorders in patients with severe acute respiratory coronavirus 2 infection: a cross-sectional study. Clin Infect Dis. 2020;71(15):889-890.

84. Kaye R, Chang CD, Kazahaya K, Brereton J, Denneny JCJOH III, Surgery N. COVID-19 anosmia reporting tool: initial findings. Otolaryngol Head Neck Surg. 2020;163(1):132-4.

85. Klopfenstein T, Toko L, Royer P-Y, Lepiller Q, Gendrin V, Zayet S. Features of anosmia in COVID-19. Med Mal Infect. 2020;50(5):436-439.

86. Lechien JR, Chiesa-Estomba CM, De Siati DR, Horoi M, Le Bon SD, Rodriguez $A$, et al. Olfactory and gustatory dysfunctions as a clinical presentation of mild-to-moderate forms of the coronavirus disease (COVID-19): a multicenter European study. Eur Arch Otorhinolaryngol. 2020;277(8):225161.

87. Mao L, Jin $\mathrm{H}$, Wang M, Hu Y, Chen $\mathrm{S}$, He Q, et al. Neurologic manifestations of hospitalized patients with coronavirus disease 2019 in Wuhan, China. JAMA Neurol. 2020;77(6):1-9.

88. Moein ST, Hashemian SM, Mansourafshar B, Khorram-Tousi A, Tabarsi P, Doty RL. Smell dysfunction: a biomarker for COVID-19. Int Forum Allergy Rhinol. 2020. https://doi.org/10.1002/alr.22587.

89. Vaira LA, Salzano G, Deiana G, De Riu GJTL. Anosmia and ageusia: common findings in COVID-19 patients. Laryngoscope. 2020;130(7):1787.

90. Yan CH, Faraji F, Prajapati DP, Boone CE, DeConde AS. Association of chemosensory dysfunction and COVID-19 in patients presenting with influenza-like symptoms. Int Forum Allergy Rhinol. 2020;10(7):806-13.

91. Song J, Deng Y-K, Wang H, Wang Z-C, Liao B, Ma J, et al. Self-reported taste and smell disorders in patients with COVID-19: distinct features in China. Preprint at https://www.medrxiv.org/content/10.1101/2020.06.12.201282 98v1.full.pdf. Accessed 5 July 2020.

92. Qiu C, Cui C, Hautefort C, Haehner A, Zhao J, Yao Q, et al. Olfactory and gustatory dysfunction as an early identifier of COVID-19 in adults and children: an international multicenter study. Otolaryngol Head Neck Surg. 2020. https://doi.org/10.1177/0194599820934376.

93. Pollán M, Pérez-Gómez B, Pastor-Barriuso R, Oteo J, Hernán MA, PérezOlmeda M, et al. Prevalence of SARS-CoV-2 in Spain (ENE-COVID): a nationwide, population-based seroepidemiological study. Lancet. 2020; 396(10250):535-544.

94. Lavezzo E, Franchin E, Ciavarella C, Cuomo-Dannenburg G, Barzon L, Del Vecchio C, et al. Suppression of a SARS-CoV-2 outbreak in the Italian municipality of Vo'. Nature. 2020;584(7821):425-429.

95. Yang X, Yu Y, Xu J, Shu H, Liu H, Wu Y, et al. Clinical course and outcomes of critically ill patients with SARS-CoV-2 pneumonia in Wuhan, China: a single-centered, retrospective, observational study. Lancet Respir Med. 2020; 8(5):475-81.

96. Xiang T, Liu J, Xu F, Cheng N, Liu Y, Qian KJ, et al. Analysis of clinical characteristics of 49 patients with novel coronavirus pneumonia in Jiangxi province. Chin J Respir Crit Care Med. 2020;19(2):1-7.

97. Young BE, Ong SWX, Kalimuddin S, Low JG, Tan SY, Loh J, et al. Epidemiologic features and clinical course of patients infected with SARSCoV-2 in Singapore. JAMA. 2020;323(15):1488-94.

98. Zhang G, Hu C, Luo L, Fang F, Chen Y, Li J, et al. Clinical features and outcomes of 221 patients with COVID-19 in Wuhan, China Preprint at https://www.medrxiv.org/content/10.1 101/2020.03.02.20030452v1.full.pdf. Accessed 20 Mar 2020.

99. Arentz M, Yim E, Klaff L, Lokhandwala S, Riedo FX, Chong M, et al. Characteristics and outcomes of 21 critically ill patients with COVID-19 in Washington state. JAMA. 2020;323(16):1612-4.

100. Mishra AK, Sahu KK, George AA, Lal AJH. Lung. A review of cardiac manifestations and predictors of outcome in patients with COVID-19. Heart Lung. 2020;50147-9563(20):30157-6.

101. Liu CJZ, Shao C, Zhang H, Yue H, Chen Z, et al. Preliminary study of the relationship between novel coronavirus pneumonia and liver function damage: a multicenter study. Chin J Hepatol. 2020;282(2020):148.

102. Li Z, Wu M, Guo J, Yao J, Liao X, Song S, et al. Caution on kidney dysfunctions of 2019-nCoV patients. Preprint at https://www.medrxiv.org/ content/10.1101/2020.02.08.20021212v2.full.pdf. Accessed 20 Mar 2020.

103. Cheng Y, Luo R, Wang K, Zhang M, Wang Z, Dong L, et al. Kidney impairment is associated with in-hospital death of COVID-19 patients. Preprint at https://www.medrxiv.org/content/10.1101/2020.02.18.20023242 v1.full.pdf. Accessed 20 Mar 2020.

104. Sahu KK, Lal A, Mishra AK. An update on CT chest findings in coronavirus disease-19 (COVID-19). Heart Lung. 2020;S0147-9563(20):30094-7. 
105. Fang $Y$, Zhang $H$, Xie J, Lin M, Ying L, Pang $P$, et al. Sensitivity of chest $C T$ for COVID-19: comparison to RT-PCR. Radiology. 2020;296(2):E115-E117.

106. Ai T, Yang Z, Hou H, Zhan C, Chen C, Lv W, et al. Correlation of chest CT and RT-PCR testing in coronavirus disease 2019 (COVID-19) in China: a report of 1014 cases. Radiology. 2020;296(2):E32-E40.

107. Bernheim A, Mei $X$, Huang M, Yang Y, Fayad ZA, Zhang N, et al. Chest CT findings in coronavirus disease-19 (COVID-19): relationship to duration of infection. Radiology. 2020;295(3):200463.

108. Song F, Shi N, Shan F, Zhang Z, Shen J, Lu H, et al. Emerging 2019 novel coronavirus (2019-nCoV) pneumonia. Radiology. 2020;295(1):210-7.

109. Xu X, Yu C, Qu J, Zhang L, Jiang S, Huang D, et al. Imaging and clinical features of patients with 2019 novel coronavirus SARS-CoV-2. Eur J Nucl Med Mol Imaging. 2020;47(5):1275-80.

110. Shi H, Han X, Jiang N, Cao Y, Alwalid O, Gu J, et al. Radiological findings from 81 patients with COVID-19 pneumonia in Wuhan, China: a descriptive study. Lancet Infect Dis. 2020;20(4):425-34

111. Pan F, Ye T, Sun P, Gui S, Liang B, Li L, et al. Time course of lung changes on chest CT during recovery from 2019 novel coronavirus (COVID-19) pneumonia. Radiology. 2020;295(3):715-21.

112. Pan $Y$, Guan $H$, Zhou S, Wang $Y$, Li Q, Zhu T, et al. Initial $C T$ findings and temporal changes in patients with the novel coronavirus pneumonia (2019nCoV): a study of 63 patients in Wuhan, China. Eur Radiol. 2020;30(6):33069.

113. Khawaja AP, Warwick AN, Hysi PG, Kastner A, Dick A, Khaw PT, et al. Associations with covid-19 hospitalisation amongst 406,793 adults: the UK biobank prospective cohort study. Preprint at https:/www.medrxiv.org/ content/10.1101/2020.05.06.20092957v1.full.pdf. Accessed 5 July 2020.

114. Palaiodimos L, Kokkinidis DG, Li W, Karamanis D, Ognibene J, Arora S, et al. Severe obesity is associated with higher in-hospital mortality in a cohort of patients with COVID-19 in the Bronx, New York. Metabolism. 2020;108: 154262

115. Shi Q, Zhao K, Yu J, Feng J, Zhao K, Zhang X, et al. Clinical characteristics of 101 non-surviving hospitalized patients with COVID-19: a single center, retrospective study. Preprint at https://www.medrxiv.org/content/10.1101/2 020.03.04.20031039v4.full.pdf. Accessed 20 Mar 2020.

116. Li X, Wang L, Yan S, Yang F, Xiang L, Zhu J, et al. Clinical characteristics of 25 death cases infected with COVID-19 pneumonia: a retrospective review of medical records in a single medical center, Wuhan, China. Int J Infect Dis. 2020;94:128-32.

117. Zhang B, Zhou X, Qiu Y, Feng F, Feng J, Jia Y, et al. Clinical characteristics of 82 death cases with COVID-19. PLoS One. 2020;15(7):e0235458.

118. Lone SA, Ahmad A. COVID-19 pandemic - an African perspective. Emerg Microbes Infect. 2020;9(1):1300-8.

119. Gao M, Yang L, Chen X, Deng Y, Yang $S, X u H$, et al. A study on infectivity of asymptomatic SARS-CoV-2 carriers. Respir Med. 2020;169:106026.

120. Gao Wenjing ZK, Ke Jl, Liming L. Advances on the asymptomatic infection of COVID-19. Chin J Epidemiol. 2020;41(0):0.

121. Zhong Wenlong HJ, Maoyu C, Liang J, Guowen P, Zhanli F, et al. A survey on a SARS nosocomial "super-spread" event (SSEs) in Jiangmen. Guangdong J Health Epidemic Prev. 2003;03:21-2.

122. Ebrahim SH, Memish ZAJL. COVID-19: preparing for superspreader potential among Umrah pilgrims to Saudi Arabia. Lancet. 2020;395(10227):e48.

123. Park Y-S, Lee C, Kim KM, Kim SW, Lee K-J, Ahn J, et al. The first case of the 2015 Korean Middle East respiratory syndrome outbreak. Epidemiol Health. 2015;37:e2015049.

124. WHO. Update 30 - Status of diagnostic test, significance of "super spreaders", situation in China. https://www.who.int/csr/sars/archive/2003_ 04_15/en/. Accessed 25 May 2020.

125. CH. Problems to be solved in SARS research in China. Epidemiol Infect Dis. 2003;(06):369.

126. Paper. T. COVID-19 "Fu Yang": there is no unified conclusion, and discharge management is being strengthened. https://www.thepaper.cn/newsDetail_ forward_6341027. Accessed 20 May 2020.

127. Paper T. Zhong Nanshan: at present, it seems that Fuyang patients are not infectious. https://www.thepaper.cn/newsDetail_forward_6473045. Accessed 25 May 2020.

128. Euronnews. Coronavirus: What is Kawasaki disease and its possible link with COVID-19 in children? https://www.euronews.com/2020/05/04/coronaviruswhat-is-kawasaki-disease-and-its-possible-link-with-covid-19-in-children. Accessed 5 May 2020.

\section{Publisher's Note}

Springer Nature remains neutral with regard to jurisdictional claims in published maps and institutional affiliations.
Ready to submit your research? Choose BMC and benefit from:

- fast, convenient online submission

- thorough peer review by experienced researchers in your field

- rapid publication on acceptance

- support for research data, including large and complex data types

- gold Open Access which fosters wider collaboration and increased citations

- maximum visibility for your research: over $100 \mathrm{M}$ website views per year

At BMC, research is always in progress.

Learn more biomedcentral.com/submissions 